\title{
Effects of urban canyons and thermal comfort in the Persian Gulf region
}

\begin{abstract}
Accessibility to thermal comfort spaces for citizens and urban outdoor activities could be one of the main goals of urban designers. The objective of this paper is to conduct a comparative study on two different urban fabrics, using thermal comfort and Computational Fluid Dynamics (CFD) methods. Results relate the effects of urban canyon's orientation on variation of the microclimate factors and consequently, on the thermal comfort situation in the hottest period of the year. The results indicate that traditional urban fabric is more thermally comfortable than the new residential urban fabric. According to the field measurements, thermal comfort calculation, and wind simulations, the canyons with NorthSouth direction represent a better orientation for air circulation benefiting from sea breezes as compared to other canyon orientations. The result will throw light for the urban designers and policy makers of hot and humid climate in the Middle East.
\end{abstract}

Keyword: Computational fluid dynamics; Hot-humid; Microclimate; Thermal comfort; Urban canyon 